\title{
Boundary condition and fuel composition effects on injection processes of high-pressure sprays at the microscopic level
}

\author{
J. Manin ${ }^{\mathrm{a}, *}$, M. Bardi ${ }^{\mathrm{b}}$, L.M. Pickett ${ }^{\mathrm{a}}$, R. Payri ${ }^{\mathrm{c}}$ \\ ${ }^{a}$ Sandia National Laboratories, 7011 East Ave, 94550 Livermore, CA \\ ${ }^{b}$ Institut Francais du Pétrol - Energies Nouvelles, Rueil-Malmaison, France \\ ${ }^{c}$ CMT Motores Térmicos, Universidad Politécnica de Valencia, Camino de Vera $s / n$, \\ 46022 Valencia, Spain
}

\begin{abstract}
Detailed imaging of n-dodecane and ethanol sprays injected in a constantflow, high-pressure, high-temperature optically accessible chamber was performed. High-speed, diffused back-illuminated long-distance microscopy was used to resolve the spray structure in the near-nozzle field. The effect of injection and ambient pressures, as well as fuel temperature and composition have been studied through measurements of the spray penetration rates, hydraulic delays and spreading angles. Additional information such as transient flow velocities have been extracted from the measurements and compared to a control-volume spray model. The analysis demonstrated the influence of outlet flow on spray development with lower penetration velocities and wider spreading angles during the transients (start and end of injection) than during the quasi-steady period of the injection. The effect of fuel composition on penetration was limited, while spreading angle measurements showed wider sprays for ethanol. In contrast, varying fuel temperature led to varying penetration velocities, while spreading angle remained constant during the quasi-steady period of the injection. Fuel temperature affected injector performance, with shorter delays as fuel temperature was increased. The comparisons between predicted and measured penetration rates showed differences suggesting that the transient behavior of the spreading angle of the sprays modified spray development significantly in the near-field. The
\end{abstract}

\footnotetext{
${ }^{*}$ Corresponding Author.

Email address: jmanin@sandia.gov (J. Manin)
}

Preprint submitted to International Journal of Multiphase Flow

August 5, 2015 
reasonable agreement between predicted and measured flow velocity at and after the end of injection suggested that the complete mixing assumptions made by the model were valid in the near nozzle region during this period, when injected flow velocities are reduced.

Keywords:

Injection, Sprays, Fuels, Microscopy.

\section{Introduction}

Liquid sprays are widely used to introduce fuel into the combustion chamber of most transportation devices relying on combustion. For the latest generation engines, particularly with the latest diesel injection strategies that utilize multiple injections, there are numerous transient processes (beginning or end of injection) during a single cycle. These transients present challenges for computational fluid dynamic (CFD) models to be predictive, whether their goal is to predict apparently simple parameters such as penetration rate or more difficult ones like the formation and mixing of liquid structures (i.e. liquid breakup and droplet size). Accurate boundary conditions such as actual injection pressure or fuel temperature in the nozzle sac are often lacking, which adds uncertainty to the true rate of injection during transients. As a result, injection and spray processes may be inexactly estimated, and blame is often placed on the computational methods rather than on the accuracy of the boundary conditions used as inputs (e.g. Vuorinen et al. (2006)). The parameters mentioned above are important to the injection process, but the rapid variations undergone through an injection event make their quantification very difficult. Indeed, Pickett et al. (2013) recently based their prediction for the actual rate of injection on measurements of spray penetration since measurements of the actual rate of injection were too uncertain during injection startup.

The near-nozzle region has attracted the interest of many researchers as it represents the initiation of the spray and an early stage of the atomization and mixing process. The flow in this region is key to understand and potentially predict the mixture distribution downstream because it affects combustion. Many CFD models treat the spray as Lagrangian particles in this first region by injecting liquid blobs through the orifice, instead of resolving the primary breakup process (Apte et al., 2003), but this approach requires solid knowledge about droplet size distribution and velocity profile (spatial and 
temporal). Issues may arise because inaccurate initial parameters generally lead to spray mixing or development errors farther downstream. In general, there is a lack of information in the region near the nozzle as probing the spray in this area is very difficult mainly because it is optically thick but also because of the high velocities and turbulent behavior of the flow.

Information about droplet size in high-pressure sprays has been obtained in the past using different diagnostics, as recently reviewed by Fansler and Parrish (2015). The caveat is that the measurements and available information mainly concern more dilute regions downstream of what is generally considered the near-nozzle. Note that there is no standard definition regarding the limits of the near-nozzle region. Pickett et al. (2014) showed that the central region of the spray retains a density equivalent to that of the liquid until approximately $3 \mathrm{~mm}$ (or about 30 orifice diameters) under the conditions applied in the present study. This means that primary atomization can be expected to dominate breakup and mixing processes in this region for high-pressure liquid flows injected into pressurized environments. Experiments have been carried out in the first millimeters by many groups using long-distance microscopy to record the development and instabilities of diesel sprays in this region (Lai et al., 1998; Heimgartner, 2000; Bae and Kang, 2006; Payri et al., 2008). The more recent iterations applying optical microscopy under engine-like conditions (high-pressure and temperature) used diffused and pulsed illumination in a line-of-sight arrangement to overcome the crippling effects of beam steering and freeze the motion (Shoba et al., 2011; Manin et al., 2014). Crua et al. (2012) used optical microscopy to measure the droplet size distribution in the near-field (although slightly farther than the limits indicated above) on the edges of the spray for two fuels under atmospheric conditions. They observed little differences between fuels and concluded that the fuel physical properties only have limited influence on droplet size. Even though the shear forces must be dominant during the quasi-steady period of the injection due to the high injection velocities and density differences, fluid properties might become relevant during transients, when injection velocities are reduced as pointed out by Manin et al. (2014). To date, the near-field microscopic research has not systematically addressed the effect of fuel injection pressure, fuel temperature, or ambient pressure on the initial spray structure and penetration.

The aim of this work is to investigate the effects of boundary conditions such as injection and ambient pressures as well as fuel temperature and 
composition on the development of sprays in the near nozzle region (up to approximately $7 \mathrm{~mm}$ or 75 nozzle diameters). Quantification of the injection processes is necessary to understand whether the potential shortcomings in modeling results are coming from variations in boundary conditions or the code itself. High speed imaging of penetrating sprays using long-distance microscopy has been implemented to resolve the macroscopic parameters of the spray both spatially and temporally with high accuracy. The sprays were injected into pressurized and slightly heated ambient conditions to prevent large temperature gradients and thus optical distortions due to beam steering.

\section{Experimental equipment and procedures}

The experimental facilities and diagnostics used in this study are introduced. We first cover the optically accessible high-pressure, high-temperature flow vessel into which the sprays have been injected, as well as the injection system. Secondly, the optical arrangement setup to probe the spray at the microscopic level is described. The image treatment and data processing performed to extract the macroscopic parameters of the spray in the near-nozzle region are detailed last.

\subsection{Pressure vessel and injection system}

Sprays have been injected in a constant flow test rig, capable of operation at a maximum ambient temperature of $1000 \mathrm{~K}$ and maximum pressure of 150 bar. The installation can be divided into four main sections: The gas compressors, heaters, the optically accessible testing section, and the control system. The gas, initially stored in high pressure reservoirs, is continuously flowed through the test chamber by volumetric compressors. Electrical heaters, placed upstream of the test chamber, increase the temperature of the flowing gas in order to reach the selected temperature within the testing section. For these tests, the system was run in a closed-loop configuration to circulate pure nitrogen and to prevent combustion of the injected fuel. The injected fuel is carried by the gas flow and is retained by a series of low-pressure filters downstream of the testing section. Both the pressure and temperature in the testing section are adjusted by a closedloop proportional-integral-derivative controller which, in order to reach and hold the temperature at or around the set-point, regulates the power to the heaters. To improve the temperature homogeneity within the test chamber, 
the vessel has a double wall configuration. The external shell's function is to hold pressure of the ambient gases, while the internal liner is an additional heater covered with insulating material on the outside to reduce heat transfer to the external wall. The testing section is relatively large (200 mm diameter) and is equipped with three fused-silica windows (128 $\mathrm{mm}$ in diameter) placed orthogonally to offer multi-view of the injection event. Further information on the design and operation of this combustion vessel are provided by Payri et al. (2012).

The experimental results reported in the present document were all performed in a slightly heated environment of $440 \mathrm{~K}$. A heated environment favors scavenging of fuel and prevents wall films between injections, while keeping evaporation of spray droplets and structures negligible during an injection event. Because the purpose of these tests is to vary injection and ambient pressures as well as fuel type and coolant temperature, keeping the vessel well below the maximum capabilities offers better control on all the parameters (especially to control injector temperature). In addition, for ambient gas temperatures typical of diesel engines closer to top-dead-center (when injection normally occurs), the optical quality is degraded because of beam steering from thermal gradients. However, as observed by Manin et al. (2014), the development (penetration rate) of sprays in the near-field is not significantly affected by changes in ambient temperature (from 440 to 900 $\mathrm{K})$. The ambient pressure has been varied from 5 to 29 bar, corresponding to ambient densities ranging from 3.8 to $22.8 \mathrm{~kg} / \mathrm{m}^{3}$. Note that the highest charge density condition is the target ambient density used by the Engine Combustion Network (ECN) for Spray A (http://www.sandia.gov/ecn/ Meijer et al. (2012); Kastengren et al. (2012); Bardi et al. (2012)).

Two fuels have been used in this study: n-dodecane and ethanol. Table 1 provides some of the specifications for both fuels that are relevant to this study. The sprays have been injected via a solenoid-driven common-rail injector belonging to the family of the Spray A ECN injectors (Serial \# 201675). This injector is equipped with a single-hole nozzle of nominal outlet diameter $0.090 \mathrm{~mm}$. The orifice is of conical shape to reduce or prevent cavitation, has an L/D of approximately 11, and hydro-grinding has been performed to round the edges and improve discharge Kastengren et al. (2012). Extensive measurements have been performed for the ECN injector set and the results of these measurements, as well as other information relevant to the present study are available in (Kastengren et al., 2012; Bardi et al., 


\begin{tabular}{ccc}
\hline Parameters & N-dodecane & Ethanol \\
\hline Chemical formula & $\mathrm{C}_{12} \mathrm{H}_{26}$ & $\mathrm{C}_{2} \mathrm{H}_{6} \mathrm{O}$ \\
Density $\left[\mathrm{kg} / \mathrm{m}^{3}\right]$ & 734 & 773 \\
Viscosity $[\mathrm{mPa} . \mathrm{s}]$ & 1.06 & 0.82 \\
Surface tension $[\mathrm{mN} / \mathrm{m}]$ & 24.3 & 20.6 \\
Vapor pressure $[\mathrm{kPa}]$ & 26.4 & 1370 \\
Boiling temperature $[\mathrm{K}]$ & 489 & 352 \\
Enthalpy of vaporization $[\mathrm{kJ} / \mathrm{kg}]$ & 256 & 846 \\
\hline
\end{tabular}

Table 1: Relevant fuel properties for n-dodecane and ethanol. Density, viscosity and surface tension are reported at $313 \mathrm{~K}\left(\approx 40^{\circ} \mathrm{C}\right), 1 \mathrm{~atm}$.; vapor pressure is given at $440 \mathrm{~K}$, boiling temperature is at $1 \mathrm{~atm}$. and the enthalpy of vaporization is at boiling temperature, $1 \mathrm{~atm}$.

2012). The nozzle is oriented with an angle of $\theta=-60^{\circ}\left( \pm 30^{\circ}\right)$ according to the conventions from the ECN, meaning that the fuel inlet is located around 2 o'clock when facing the injector. Injection pressure has been varied between 30 and $150 \mathrm{MPa}$. In this study, we set the electronic duration to a constant value $(790 \mu \mathrm{s})$ equivalent to a $1.5 \mathrm{~ms}$ injection duration under the Spray A condition (150 MPa injection pressure, 60 bar ambient pressure). When injection and/or ambient pressure is varied, injection duration changes widely as shown in the results presented further in this manuscript, where the phenomenon is detailed and discussed.

As mentioned in the introduction, the temperature of the fuel could play an important role on the injection processes by affecting fuel properties. For that reason, the spray rig is equipped with a temperature-controlled injector holder in which a liquid coolant is flowed through to ensure that the injector body is at the desired temperature. The temperature of the injector body has been varied from 30 to $80^{\circ} \mathrm{C}$ (303 to $353 \mathrm{~K}$, respectively). Note that the actual temperature of the nozzle tip (sac) has been measured thanks to a thermocouple probe mounted into a dummy injector made from another Spray A ECN injector unit. The results of these measurements are detailed in Refs. (Payri et al., 2012; Meijer et al., 2012). Because the vessel is only slightly heated, the temperature of the fuel is expected to be very close to that of the coolant; based on the thermocouple measurements mentioned above, the fuel temperature is believed to be within $5^{\circ} \mathrm{C}$ above the coolant temperature. When coolant temperature is not varied to investigate the effect of fuel temperature on injection processes, the liquid is running at $42^{\circ} \mathrm{C}$ around the injector, the fuel in the sac being at $42^{\circ} \mathrm{C}(315 \mathrm{~K})$ as well. The results presented later regarding fuel temperature variations are related 


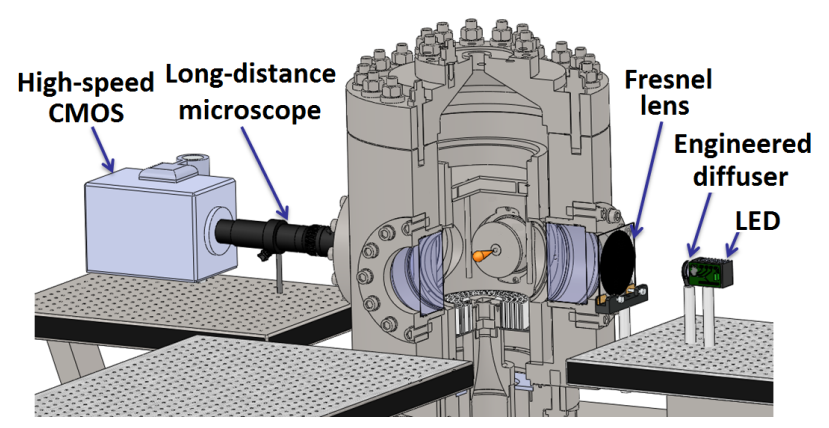

Figure 1: Schematic of the experimental arrangement showing the combustion vessel in the center, the long-distance microscope imaging system on the left and the illumination setup on the right.

to coolant temperature as this is the controlled parameter.

\subsection{Optical arrangements}

The sprays have been visualized employing a line-of-sight arrangement based on diffuse lighting similar to the one described by Ghandhi and Heim (2009). Diffused back-illumination has been utilized in this study to provide an efficient and uniform illumination reducing the effects of beam steering due to the heated and pressurized environment inside the vessel. As remarked by others (Manin et al., 2014; Crua et al., 2012), performing detailed imaging of the spray in the near-nozzle field is very challenging as the spray exits the nozzle at speeds of several hundred meters per second (flow velocity may exceed $600 \mathrm{~m} / \mathrm{s}$ at $150 \mathrm{MPa}$ pressure drop). Therefore the image duration must be kept small to record the spray so that the image appears motionless. In this work, short pulses of light were used to acquire the fast-moving sprays in a motionless manner. The lighting was therefore provided by an ultra-fast LED system developed at Sandia National Laboratories that is capable of generating bursts of light as short as 20 ns at high repetition rates (several $\mathrm{MHz}$ ). The LED system is equipped with a quad-die LED chip and the pulse duration was set to $50 \mathrm{~ns}$ to provide powerful yet short illumination. The illumination's spectrum is centered around $450 \mathrm{~nm}$ with a $20 \mathrm{~nm}$ bandwidth. A $20^{\circ}$ engineered diffuser is mounted in front of the LED (at approximately $15 \mathrm{~mm}$ from the emitter) to collect and diffuse the light from the LED toward a $70 \mathrm{~mm}$ focal length Fresnel lens with an effective diameter of $125 \mathrm{~mm}$ used to focus the illumination onto the region of interest for greater efficiency. 
The images were recorded by a high-speed camera equipped with a 12bit CMOS sensor with $20 \mu \mathrm{m}$ pixel size (Photron SA-5). The images were acquired from the $+Z$ position corresponding to $\theta=90^{\circ}$ based on the nozzle orientation convention mentioned earlier. A long-distance microscope lens (Infinity KV) was mounted to the camera to offer detailed optical access of the near-nozzle region. Further information concerning the specifications and limitations of the optical system described above have been listed and detailed by Manin et al. (2014). The camera was synchronized with the electronic control system of the injector, to obtain consistent time-delay while providing information with respect to hydraulic jittering. Different frame rates, image resolution and magnifications have been used throughout the experiments depending on the parameter of interest: Magnification ratio ranged from 1.2 to $2.6 \times(7.8$ to $16.9 \mu \mathrm{m}$ per pixel $)$, while frame rate has been varied from 50 thousand frames-per-second (kfps) to up to $263 \mathrm{kfps}$. The schematic of Fig. 1 shows the testing section of the combustion vessel in the center surrounded by the illumination system on the right side and the high-speed camera with the microscope lens on the other side as arranged for the experiments performed in this work. Note that as mentioned earlier, the optical system has been optimized such that the effects of beam steering are reduced. This has been achieved on the illumination side by widening the diffuse angle of the light rays up to $230 \mathrm{mrad}$. The collection was maximized on the acquisition side by placing the microscope lens at approximately 250 $\mathrm{mm}$ from the spray, which offered a collection angle in excess of $150 \mathrm{mrad}$.

\subsection{Image processing}

The background correction procedure applied to the images included dividing the images of the injection event (I) by the initial intensity $\left(\mathrm{I}_{0}\right)$ as a normalization method to overcome non-homogeneities in lighting distribution (due to beam steering or other optical artifacts). The initial intensity is taken from an average of several images immediately before injection. The result is a shadowgraph image with the imaging system being sensitive to the attenuation of light produced by the spray mainly due to Mie scattering (molecular absorption is negligible and beam steering is significantly reduced thanks to the optical system in place). Figure 2 represents a near-field penetration sequence of an n-dodecane spray injected at $50 \mathrm{MPa}$ into relatively low ambient density $\left(3.8 \mathrm{~kg} / \mathrm{m}^{3}\right)$. Note that the camera frame rate for the penetration tests was $263 \mathrm{kfps}$ (time step $=3.8 \mu \mathrm{s}$ ), but this sequence only represents every other image, or every $7.6 \mu \mathrm{s}$, highlighting the detailed time- 


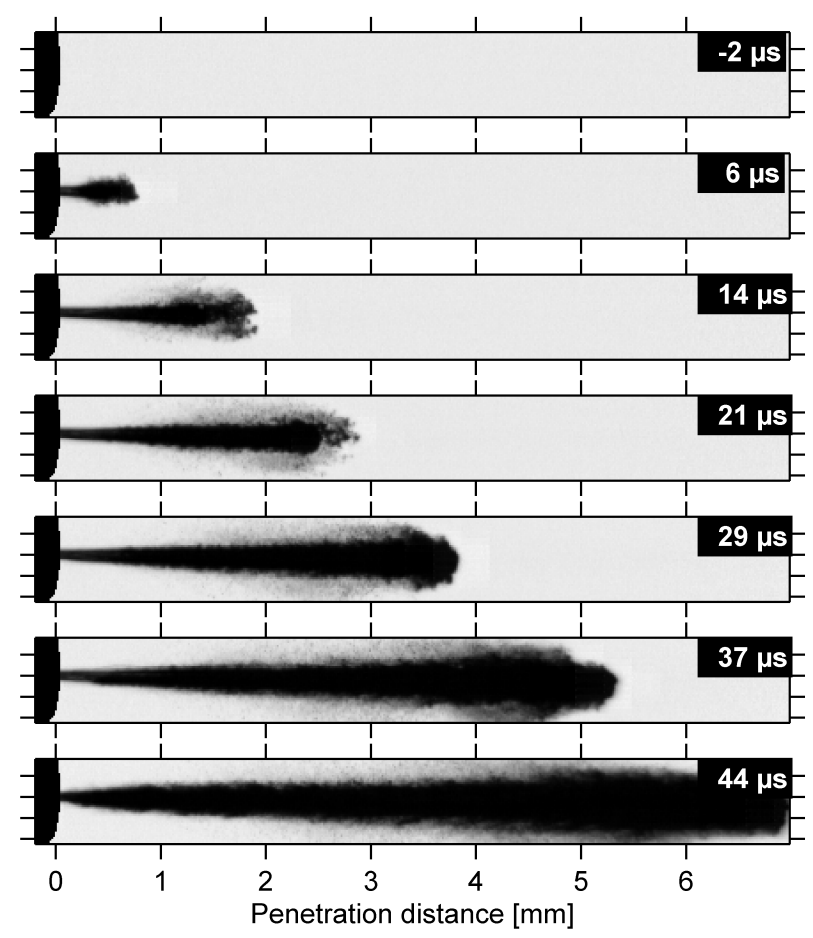

Figure 2: Normalized image sequence showing the development of an n-dodecane spray injected at $50 \mathrm{MPa}$ into an ambient density of $3.8 \mathrm{~kg} / \mathrm{m}^{3}$. Timings at the top-right corner represent the time after the start of injection.

resolution of the penetration data considering the velocity of the flow and the relatively small field of view.

The image quality is essential in such work, especially when focusing on spray edges as the relatively low fuel concentration might be below the detection limit of the system. Image blurring or lack of focus are other issues affecting the performance of the system as the edges of the spray would lack sharpness (particularly when measuring spreading angle). The vessel being heated to $440 \mathrm{~K}$, non-uniform gradients in gas temperature (or density) could cause steering of the rays of light (beam steering) traveling through the testing section. These gradients are more severe at high pressure, thus modifying the refractive index map throughout the pressurized section and bending the rays in different directions.

Because of the line-of-sight arrangement, resulting in a shadowgram, the spray has been identified from the background basing the processing on a 
constant extinction threshold. Pickett et al. (2014) conducted a comparative experiment between back-illuminated long-distance microscopy and $\mathrm{x}$ ray radiography to determine the sensitivity of $\mathrm{x}$-ray to fuel concentration and correlate optical extinction to liquid volume fraction. They concluded that an optical extinction of optical depth $(\tau)=1$ was equivalent to a liquid volume fraction of approximately $1 \%$ on the edges of a spray under similar experimental arrangements and conditions. Therefore, the results presented throughout this document have been derived from two-dimensional optical extinction measurements assuming that the edges of the spray are located at $\tau=1$. Note that it has been observed that the sensitivity of the spray contour to the extinction threshold was limited because of the sharp gradient in optical extinction on the edges of the spray.

Several parameters can be extracted from time-resolved spray boundary. Two parameters were extracted directly from the processed images:

- Spray tip penetration: The furthest axial distance from the nozzle exit where the spray was detected based on the method described above was taken as maximum spray tip penetration at each time-step.

- Spreading angle: The spreading angle of the sprays has been measured to get a time-resolved description of the spray radial growth by fitting two lines on either sides of the spray between 1 and $2 \mathrm{~mm}$ downstream of the orifice exit.

From the two macroscopic parameters detailed above, two additional variables have been extracted:

- Spray penetration velocity: The velocity of the spray in the first instants of the injection has been calculated to better quantify the differences in spray penetration when varying boundary conditions. The penetration distance with respect to time has been time-derived to obtain penetration velocity in the near-field.

- Hydraulic delay: The hydraulic delay corresponds to the time delay between energizing of the solenoid actuator driving the injector's needle (injector command) and actual injection of fuel through the nozzle outlet. Note that spray penetration and spreading angle reported next are corrected for this delay and presented with respect to the time after start of injection (ASOI). 
The high velocities of the flow make the time measurement accuracy a primary issue. In the tests performed, we observed small jitter from the electronics employed (coming from the camera or the timing system for example) and/or from the mechanical actuation of the injector. Because changing the conditions affects the hydraulic delay, the system requires a certain time to adjust and be repeatable (to minimize shot-to-shot variations). Sufficient time has been taken between experiments to allow the system to stabilize, however, small variations in boundary conditions such as injection pressure (generally within $1 \mathrm{MPa}$ ) or coolant temperature (regulated to $\pm 2^{\circ} \mathrm{C}$ ), are beyond our control and their effect on hydraulic delay would be interpreted as jittering. Whether the jittering comes from fluctuations in the boundary conditions (hydraulic) or slight deviations from the electronic timing system, this increases the uncertainty in the quantification of the hydraulic delay and a fortiori on spray penetration. The start of hydraulic injection is calculated by linear extrapolation back to the injector exit location of the first two spray frames. The results are all compiled from several injection events, from 5 to 20 high-speed recordings (injections), depending on the conditions and test performed. A statistically based estimation of the uncertainty (jitter) in the measurements of the hydraulic delay can be obtained from the standard deviation during one set of experiments. The standard error of the mean (Brown, 1988) provides an estimate for the uncertainty in hydraulic delay below $9 \mu \mathrm{s}$ in the worst case scenario, corresponding to the lower injection pressure condition. This is expected to be well below the identified differences observed during the variations in boundary conditions reported in the next section. Note that only the results of hydraulic delay suffer from jittering, which is reported as error bars on the data presented in the next section; the penetration rate and spreading angle results have been corrected from the jitter for better time alignment.

\section{Experimental results and discussions}

\subsection{Influence of injection and discharge pressures}

Figure 3 shows the influence of injection pressure and ambient density on the penetration rate of n-dodecane sprays in the near-field (up to $7 \mathrm{~mm}$ ). The penetration rates for the several repetitions performed (10 in this case) are plotted as data point, which after time alignment (jitter correction), show very repeatable slopes across the different repeated injections. 


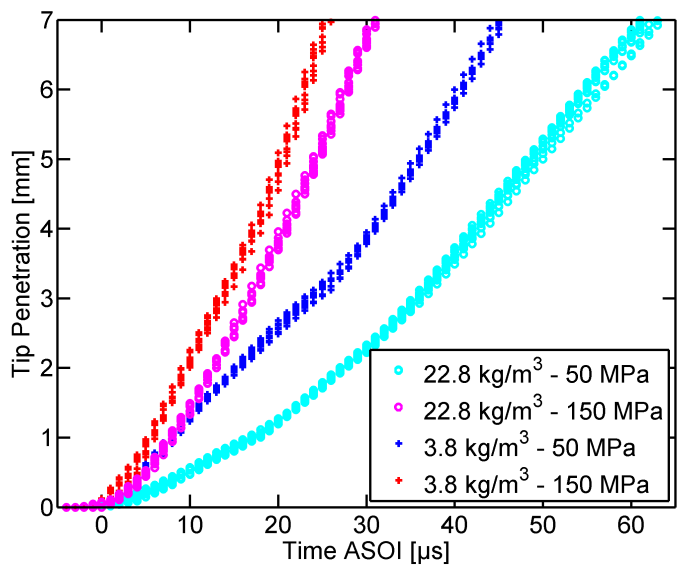

Figure 3: Spray tip penetration in the near-field as a function of time for n-dodecane fuel at two injection pressures and two ambient densities.

As expected, the penetration rates in Fig. 3 increase with injection pressure. The unique time-resolution of these experiments supports the transient behavior of the penetration rates. The effect of ambient density represented by the different symbols is also as expected as lower ambient pressure produces faster penetrating sprays due to a slower entrainment rate of ambient gases (Naber and Siebers, 1996). The increasing slope of the curves demonstrate that the sprays accelerate in the first instants of the injection process (especially obvious for the lower injection pressure), which suggests an increase in injection velocity at the nozzle exit. An increased injection velocity is expected as fuel pressure ramps up in the nozzle (sac and orifice) while the needle opens.

The penetration velocity, the time-derivative of the tip penetration, shown in Fig. 4 highlights the acceleration of the sprays with more clarity. All cases experience an increase in penetration velocity, but the velocity increase may occur when the tip is at a different axial position. The ramp-up in penetration velocity as the injector opens and pressure builds up in the sac (over the first 25 to $60 \mu$ s for these injection conditions) is countered by momentum transfer from the ambient gas, causing spray deceleration. Penetration velocities reach maximum values (around the end of the visualization window at 6 $\mathrm{mm}$ ) as confirmed by separate far-field imaging from Pickett et al. (2013) but never reach the Bernoulli velocities of the flow expected at the nozzle exit. The high-speed imaging results confirm the ramping rate of injection 


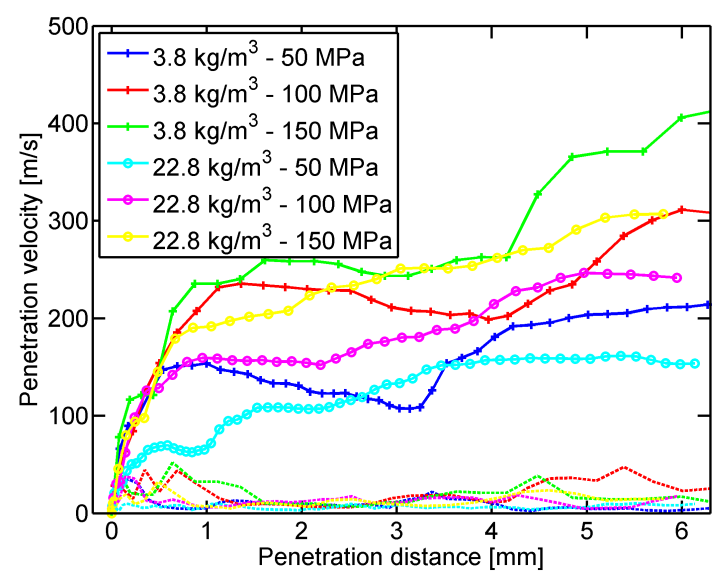

Figure 4: Velocity of the tip penetration in the near-field as a function of penetration distance for three injection pressures and two ambient densities. The dashed-lines at the bottom of the graph represent the standard deviation of the experiments.

observed by Pickett et al. (2013).

The effects of injection and discharge pressures on the start of injection (hydraulic delay) are shown in Fig. 5. The vertical error bars report the standard deviation measured over the different repetitions during the experiments.

Fig. 5 quantifies the influence of injection pressure on hydraulic delay, as sprays exit the nozzle earlier after the command signal for higher injection pressures. This behavior seems logical as the injector used in this study is electro-hydraulically controlled. The solenoid-driven valve opens the control volume located on the other end of needle mechanism, which allows the pressure to drop, hence inducing a pressure difference on both ends of the injector needle mechanism. The high pressure at the bottom of the assembly, near the nozzle exit, forces the needle to lift from the seat, allowing the fuel to flow to the sac and orifice. Supplying the injector with higher fuel injection pressure increases the force exerted by the fuel on the needle in the nozzle region, thus lifting the needle earlier and faster. Details about the mechanics of such injector is available in Ref. (Manin et al., 2012).

Spreading angle is an important parameter as it describes the mixing of sprays in the near-field. Wider sprays, or larger spreading angles, are expected to entrain more air as they develop (Pickett et al., 2011). Figure 6 


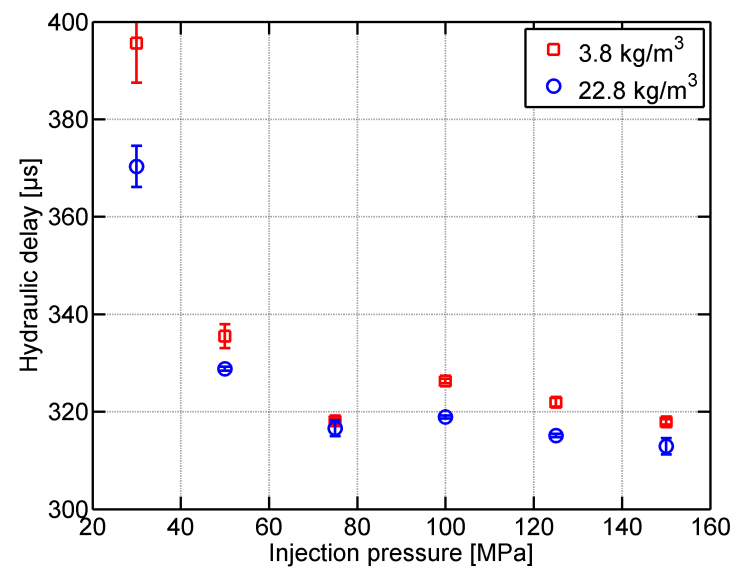

Figure 5: Hydraulic delay as a function of injection pressure for n-dodecane fuel into two ambient densities.

plots the spreading angle with respect to time for n-dodecane at three injection pressures injected and two ambient densities. We remind the reader that the outside border of the spray is defined using an optical extinction of $\tau=1$. The standard deviation computed over the different repetitions is plotted as dashed-lines at the bottom of the graph. The standard error of the mean for the time-resolved measurements of spreading angle is below $1.2^{\mathrm{O}}$ in the worst case scenario. This uncertainty drops down to $0.2^{\mathrm{O}}$ when only the quasi-steady period of the injection is considered.

A change in injection pressure produces significant differences in spreading angle, with changes in transient and quasi-steady periods. Focusing on the transient period corresponding to the start of injection first, the sprays are several degrees wider than during the quasi-steady period under all conditions. The difference between injection pressures is manifested through the duration of this transient start of injection; a quicker transient occurs when high injection pressure is applied, while it is more than twice as long for a low injection pressure. This behavior is believed to come from a needle effect as it throttles the passage of the fuel to the sac and orifice, as has been experimentally observed by Payri et al. (2013). The slower penetrating sprays of the low injection pressure case may have a longer residence time in the near-nozzle region, thus affecting the spreading angle quantities. Injection pressure changes the speed at which the needle lifts from the seat, with higher injection pressures increasing the lift speed, as measured by Kastengren et al. 


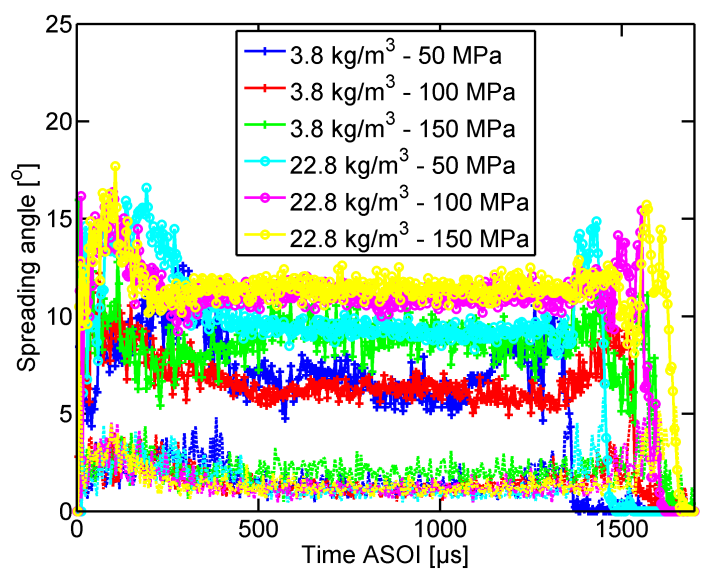

Figure 6: Spray spreading angle as a function of time for n-dodecane fuel sprays at three injection pressures and two ambient densities. The dashed-lines at the bottom of the graph represent the standard deviation of the experiments.

(2011). The different slopes in penetration and velocity with respect to time (Figs. 3 and 4 ) are also consistent with the spreading angle measurements shown in Fig. 6, which confirm the effect of needle position on spray development. During the quasi-steady period of the event, the differences in spreading angle are obvious, with higher injection pressure producing wider sprays. The transient period corresponding to the end of injection shows that injection ends earlier for the low injection pressure case. In fact, while the electronic signal to control the injection duration has been kept constant (Energizing time $=790 \mu \mathrm{s}$ ), the actual injection duration is longer when injection pressure goes up as observed by Kastengren et al. (2011) for the same family of injectors. This comes from the faster needle lift at higher injection pressure, allowing the needle to reach a higher position (farther from its seat) at the time the command signal ends, and while needle closing is also faster at higher injection pressure (but not as fast as opening), it does not allow the needle to come back to its seat at the same time.

\subsection{Fuel composition effects}

The effect of injected fuel properties on spray penetration is displayed in Fig. 7. Three injection pressures are shown, with the sprays injected into an environment maintained at an ambient density of $22.8 \mathrm{~kg} / \mathrm{m}^{3}$.

Figure 7 shows that the effects of fuel properties on the near-field penetra- 


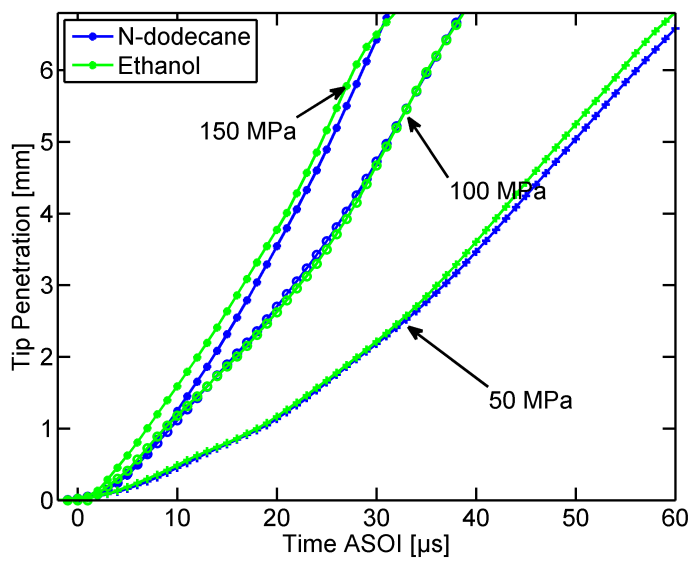

Figure 7: Spray tip penetration for n-dodecane and ethanol as a function of time for three injection pressures. Ambient density is $22.8 \mathrm{~kg} / \mathrm{m}^{3}$.

tion are minimal, with nearly identical spray developments whether ethanol or n-dodecane is injected. These observations agree with the fact that spray penetration is mainly momentum driven, and that physical fluid properties have limited effects on spray momentum. For instance, Desantes et al. (2009) investigated the influence of fluid properties on spray development from a macroscopic point of view (up to $40 \mathrm{~mm}$ downstream of the injector) by comparing diesel and biodiesel fuels, and observed that the differences were negligible when global penetration is concerned. In addition, the differences in physical fluid properties for the two fuels compared in Fig. 7 are relatively small, hence giving confidence toward the observations.

The effects of both fuel and ambient density on hydraulic delay are plotted in Fig. 8 as a function of injection pressure. As a general trend, it appears that the hydraulic delay gets shorter as injection pressure increases. This seems reasonable because higher forces would be applied to the needle in the nozzle region, thus helping the needle to lift. The first lift of the needle described earlier is believed to allow liquid to flow to the sac and pressurize it up to the cracking pressure of the injector (roughly $20 \mathrm{MPa}$ ). Once the sac is pressurized, the needle lifts and opens the gap to allow the flow to circulate downstream to the sac and the fuel to be injected through the orifice. One could expect higher flow rate to pressurize the sac more quickly during the initial lift stage of the needle, thus producing a faster response of the needle 


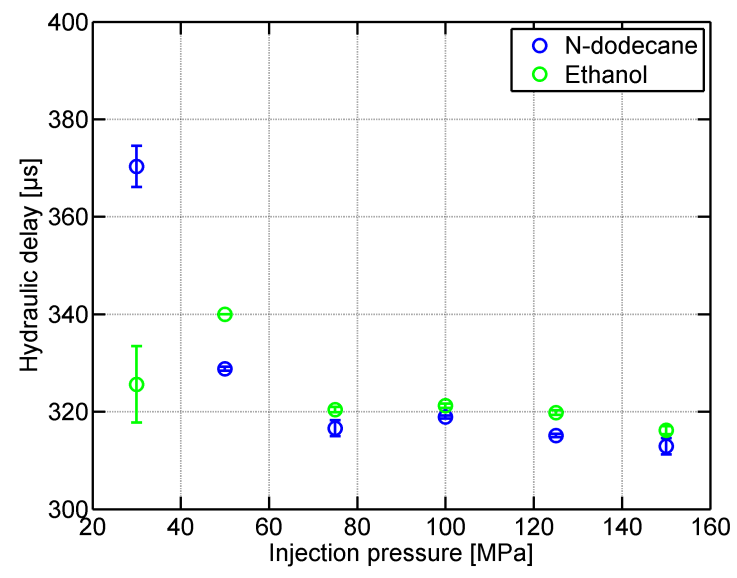

Figure 8: Hydraulic delay as a function of injection pressure for n-dodecane and ethanol into two ambient densities.

to lift.

The results plotted in Fig. 8 indicate that the hydraulic delay is shorter for ethanol at $30 \mathrm{MPa}$, while slightly longer at higher injection pressures. The variability in hydraulic delay with hydraulically-actuated injectors at relatively low operating pressure has been observed in many instances. The standard deviation ranges from 10 to $20 \mu \mathrm{s}$, for n-dodecane and ethanol, respectively, or at least $10 \times$ more than at other pressures. The observations made from Fig. 8 do not allow drawing solid conclusions with respect to the hydraulic delay between n-dodecane and ethanol. At the same time, the quantities in Table 1 do not report significant variations in viscosity between ethanol and n-dodecane and hence, limited effect should be expected. Note that other fuels commonly used in thermal engines may present larger variations in physical properties, particularly viscosity (e.g. biofuels). For instance, the measurements reported by Desantes et al. (2009) showed longer hydraulic delay for biodiesel fuel (higher viscosity) when comparing the injection rate of rape methyl ester to diesel fuel.

The spreading angle of the sprays can also shed some light on the possible differences between fuels, even though the results presented above for ndodecane and ethanol did not support major impact of fuel properties on injection processes and spray development. Figure 9 represents the spreading angle with respect to time in the near-field for the two fuels tested. N- 


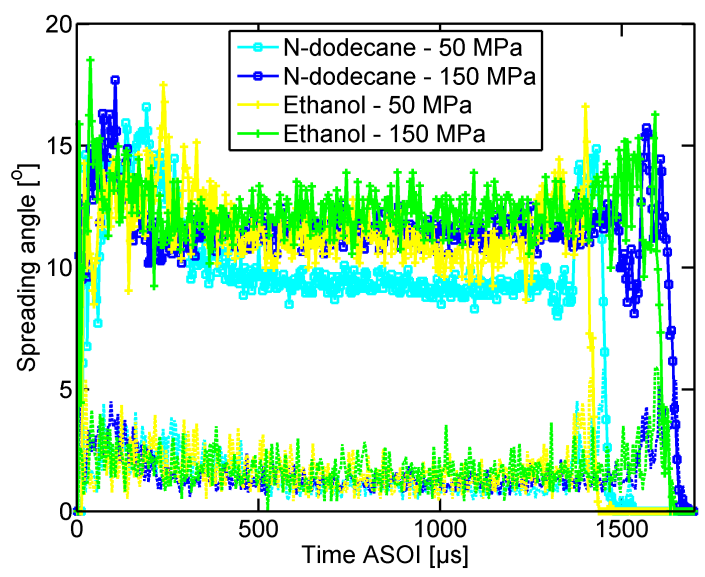

Figure 9: Spreading angle of the sprays as a function of time for n-dodecane and ethanol at two injection pressures. Ambient density is $3.8 \mathrm{~kg} / \mathrm{m}^{3}$. The dashed-lines at the bottom of the graph represent the standard deviation of the experiments.

dodecane and ethanol sprays are compared here for two injection pressures into an ambient density of $3.8 \mathrm{~kg} / \mathrm{m}^{3}$.

Although the transient periods at the start and end of injection behave similarly for n-dodecane and ethanol, it is not the case for the quasi-steady period with ethanol producing wider sprays for both injection pressures represented in Fig. 6. It is more obvious at lower injection pressure where the difference is around $2^{\mathrm{O}}$ on average during the quasi-steady period. Based on the similar penetration rates observed for these two fuels in Fig. 7 and the strong relationship between penetration rate and spreading angle found by Pickett et al. (2011), such differences in spreading angle are rather surprising. However, the penetration rates correspond to the very beginning of the injection, which are not necessarily related to the quasi-steady spreading angles, as shown earlier. These results were confirmed through analysis of the radial extinction profiles for both fuels taken on the average images during the quasi-steady period. One reason can be put forward to explain this behavior, which is that cavitation affects ethanol significantly more than n-dodecane. Based on previous experiments with this injector, no cavitation has been observed when n-dodecane is injected, but cavitation is affected by fluid properties, especially vapor pressure. The higher vapor pressure of ethanol compared to n-dodecane under similar conditions (same fuel temperature) is expected to increase the propensity for cavitation. Hydraulic 


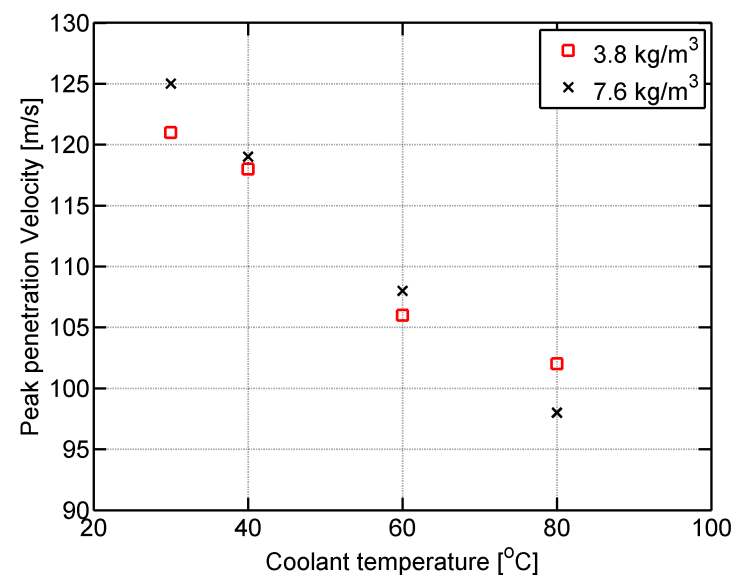

Figure 10: Maximum spray penetration velocity measured until $3 \mathrm{~mm}$ from the nozzle outlet as a function of coolant temperature for n-dodecane into two ambient densities. Injection pressure is $50 \mathrm{MPa}$.

measurements or comparison of the tip penetrations in the far-field might also provide valuable information in that respect.

\subsection{Fuel temperature effects}

The effect of fuel temperature on penetration has also been studied through calculation of the penetration velocity at a certain distance. Based on the relatively small field of view during these specific experiments, the penetration velocities have been measured only until approximately $3 \mathrm{~mm}$ (end of the visualization window). Lower quantities than the peak velocities shown in Fig. 4 are therefore expected as the penetration rates are still increasing at such distances. Nevertheless, the velocities in this region should be representative of the trends regarding the near-nozzle spray penetration when fuel temperature is varied. Figure 10 plots the maximum penetration velocity of sprays in the first three millimeters while varying coolant temperature from 30 to $80^{\circ} \mathrm{C}$ (303 to $\left.353 \mathrm{~K}\right)$. N-dodecane sprays were tested in two discharge densities and at a relatively low injection pressure of $50 \mathrm{MPa}$. Note that we estimate the uncertainty to be within approximately $7 \mathrm{~m} / \mathrm{s}$ in the worst case scenario presented in Fig. 10.

From Fig. 10, the effect of fuel temperature on penetration rate is evident as the sprays penetrate faster in the chamber as coolant temperature (fuel temperature) is lower. This is an interesting observation as fuel density 


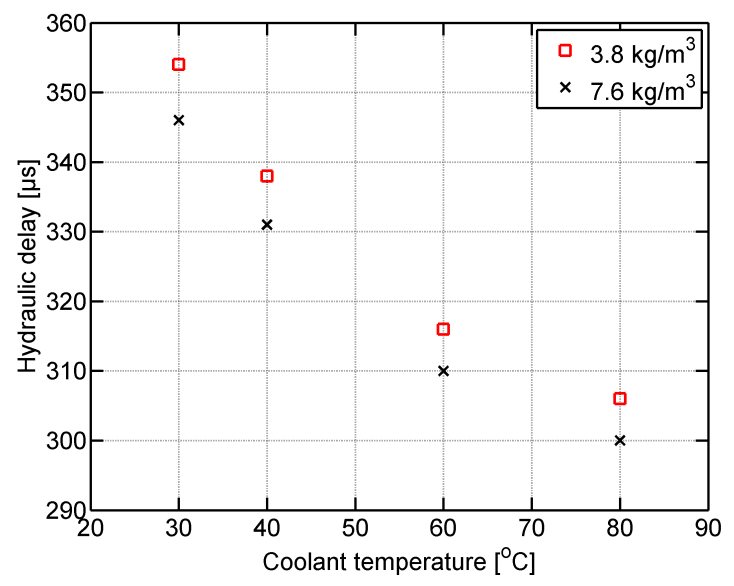

Figure 11: Hydraulic delay as a function of coolant temperature for n-dodecane into two ambient densities. Injection pressure is $50 \mathrm{MPa}$.

decreases when temperature rises. For instance, the measurements performed by Caudwell et al. (2004) for n-dodecane at $50 \mathrm{MPa}$ showed a reduction in density from 774 to $745 \mathrm{~kg} / \mathrm{m}^{3}$ when fluid temperature varies from 30 to $80^{\circ} \mathrm{C}$, in that order. Based on the Bernoulli velocity at the orifice outlet, lower fuel density would translate into higher flow velocity, but the differences displayed on Fig. 10 are larger than the ones suggested by the change in fuel density.

Viscosity is another parameter known to affect internal flow and injection processes; the viscosity for n-dodecane at $50 \mathrm{MPa}$ goes from 2.17 to 1.05 mPa.s when temperature varies from 30 to $80^{\circ} \mathrm{C}$ (Caudwell et al., 2004), respectively. A lower fluid viscosity would favor the flow from upstream the needle seat down to the sac of the nozzle tip. If the sac is filled with liquid faster than for lower viscosity (lower fuel temperature) cases, one can expect the liquid to come out of the orifice sooner, as shown in Fig. 10.

The effects of fuel temperature on the delay at the start of injection (hydraulic delay) are shown in Fig. 11. The conditions are the same as those of Fig. 10, with two ambient densities and an injection pressure of $50 \mathrm{MPa}$.

The plot in Fig. 11 demonstrates the influence of fuel temperature on hydraulic delay, as sprays exit the nozzle earlier after the command for higher coolant temperature, which therefore validates the hypothesis made after Fig. 7. This behavior is believed to be attributed mainly to the viscosity of 
the fuel for the reasons developed earlier. In addition to the fact that the fluid is flowing at higher rate through the seat and needle within the nozzle region, another influence of viscosity may come from the working principle of the injector as it is electro-hydraulically driven by the pressure difference across the valve of the control volume located above the needle mechanism, as detailed earlier. Higher viscosity is expected to reduce the flow through the control volume, which would delay pressure balancing and the subsequent needle lift. Lower viscosity (for higher coolant temperature) is also going to reduce the contact friction between moving parts which could also favor faster needle lift. Based on the results of Fig. 5, one should expect higher ambient density to reduce hydraulic delay.

Fuel properties known to affect spray dispersion under matching boundary conditions (mainly density, viscosity and surface tension) are similar for n-dodecane and ethanol. The hypothesis formulated above pointed at cavitation inside the nozzle to explain the differences in spreading angle between the two fuels. A cavitating flow would modify the velocity distribution exiting the orifice when compared to a non-cavitating flow. This picture can be affected by varying fuel temperature as it may change fuel behavior and characteristics, potentially affecting injection processes. Figure 12 represents the spreading angle with respect to time in the near-field for n-dodecane and ethanol at two coolant temperatures $\left(30\right.$ and $\left.80^{\circ} \mathrm{C}\right)$. The injection pressure and ambient density are kept constant at $50 \mathrm{MPa}$ and $3.8 \mathrm{~kg} / \mathrm{m}^{3}$, respectively. Note that intermediate temperatures have been tested but are not represented in this graph for clarity.

The effect of fuel (coolant) temperature on spreading angle is small but visible in Fig. 12, with a reduction in spray dispersion when fuel temperature is increased. The relative differences between the lowest $\left(30^{\circ} \mathrm{C}\right)$ and the highest $\left(80^{\circ} \mathrm{C}\right)$ temperatures tested are similar for both fuels, hence not supporting cavitation for ethanol compared to n-dodecane, as hypothesized after Fig. 9. The same differences observed in Fig. 9 between the two fuels seem to appear in this plot as well for both coolant temperatures.

\section{Transients and modeling considerations}

Transients often present high challenges for models, specifically in the near-field. This is partly due to inaccurate knowledge about boundary conditions such as real rate of injection or injection velocity during the opening 


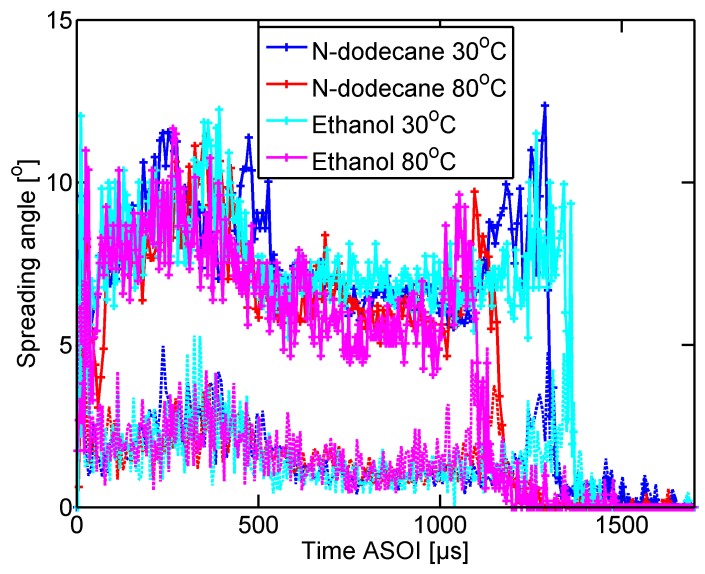

Figure 12: Spreading angle of the sprays in the near-nozzle region as a function of time for n-dodecane and ethanol at two coolant temperatures. Injection pressure is $50 \mathrm{MPa}$ and ambient density is $3.8 \mathrm{~kg} / \mathrm{m}^{3}$. The dashed-lines at the bottom of the graph represent the standard deviation of the experiments.

and closing of the injector, among other parameters. While the influence of injection and discharge pressures on penetration rate in the far-field has been demonstrated by many, only a few studies (e.g., Payri et al. (2008)) previously reported on their impact in the near-field. Understanding the relationship between boundary conditions and actual spray penetration is important as some spray models do not account for ambient density at the very beginning of the spray development in what is commonly called the non-perturbed region (Desantes et al., 2005). Pickett et al. (2013) investigated the implication of rate of injection and spray shape (spreading angle) on near-field penetration rate using the control-volume model jet proposed by Musculus and Kattke (2009). The same model has been used in the present work to quantify the differences between experimentally measured and simulated penetration rates.

The Musculus and Kattke model is an extension of the uniform-profile non-vaporizing model proposed by (Naber and Siebers, 1996). The variableprofile model adds the option to predict a realistic radial distribution of fuel mass and velocity at any axial distance from the injector. The original purpose of the variable-profile model was to simulate penetration and mixing during and after the end of injection for variable rates of injection. To do so, the variable-profile model used a one-dimensional numerical control-volume 
solution, discretized along the spray axis. This model is still based on the mixing concept used in the previous model from Naber and Siebers: The control-volume model assumes complete momentum transfer (or no velocity slip) as seen in gas jet mixing. This means that when comparing experimental data from turbulent two-phase flows with the model, any deviation from complete momentum transfer between liquid and gas would not be correctly predicted by the model, which is what makes this modeling approach interesting in this case. If the model accurately predicts initial spray penetration or end of injection velocities, it means that the momentum transfer between the spray and the surrounding gas is rather complete. More detailed simulations such as three-dimensional Rayleigh average Navier-Stokes (RANS) or large eddy simulations (LES) are useful in many cases, but they generally account for aerodynamic interactions and drag, absent from the control-volume model, allowing us to evaluate their effects on spray development and entrainment rate in the present study.

For the model to deliver potentially comparable penetration rates, accurate knowledge about the boundary conditions is necessary. The rate of injection and the spreading angle are two of the most important parameters driving the rate of penetration of the injected sprays (Pickett et al., 2013). Fortunately, the rate of injection of the ECN Spray A injectors has been extensively characterized by several institutions, collecting data which has been gathered into a rate of injection generator available online: http://www.cmt.upv.es/ECN09.aspx. Supported by optical measurements, Pickett et al. (2013) found that the spreading angle had to be modified in the near-field (up to $10 \mathrm{~mm}$ ). The spreading angle values used as input to the model correspond to the quantities measured during the transient start of injection. Even though it can be argued that using a fixed spreading angle during the start of injection is inappropriate due to rapidly varying quantities, the model does not allow for time-dependent spreading angle. It is worth noting that the spreading angle values reported in Figure 9 are based on an optical extinction of $\tau=1$, which may reduce spray opening; however, lower extinction levels (e.g., $\tau=0.1$ ) do not produce larger spreading angle values. Table 2 lists the relevant input parameters to the spray model as well as the boundary conditions used to simulate the rate of injection with the virtual injection rate model mentioned above. Similarly to the spreading angle, the rate of injection is dependent upon the operating conditions, and is hence function of injection and discharge pressures. 


\begin{tabular}{|c|c|c|c|c|}
\hline Parameters & $\begin{array}{c}3.8 \mathrm{~kg} / \mathrm{m}^{3} \\
50 \mathrm{MPa}\end{array}$ & $\begin{array}{l}3.8 \mathrm{~kg} / \mathrm{m}^{3} \\
150 \mathrm{MPa}\end{array}$ & $\begin{array}{c}22.8 \mathrm{~kg} / \mathrm{m}^{3} \\
50 \mathrm{MPa}\end{array}$ & $\begin{array}{r}22.8 \mathrm{~kg} / \mathrm{m}^{3} \\
150 \mathrm{MPa}\end{array}$ \\
\hline Nozzle diameter [mm] & \multicolumn{4}{|c|}{0.0894} \\
\hline Discharge coefficient & \multicolumn{4}{|c|}{0.90} \\
\hline Area coefficient & \multicolumn{4}{|c|}{0.98} \\
\hline Mass flow rate $(\max )[\mathrm{g} / \mathrm{s}]$ & 1.59 & 2.70 & 1.53 & 2.68 \\
\hline Injection duration $[\mathrm{ms}]$ & \multicolumn{4}{|c|}{1.5} \\
\hline Run time $[\mathrm{ms}]$ & \multicolumn{4}{|c|}{2.0} \\
\hline Fuel density $\left[\mathrm{kg} / \mathrm{m}^{3}\right]$ & \multicolumn{2}{|c|}{703} & \multicolumn{2}{|c|}{725} \\
\hline Injection pressure $[\mathrm{MPa}]$ & 50 & 150 & 50 & 150 \\
\hline Discharge pressure [MPa] & 0.5 & 0.5 & 2.9 & 2.9 \\
\hline Spreading angle $\left[{ }^{\circ}\right]$ & 9 & 12 & 10 & 14 \\
\hline
\end{tabular}

Table 2: Relevant boundary conditions for the simulated rate of injection and inputs to the Musculus and Kattke model.

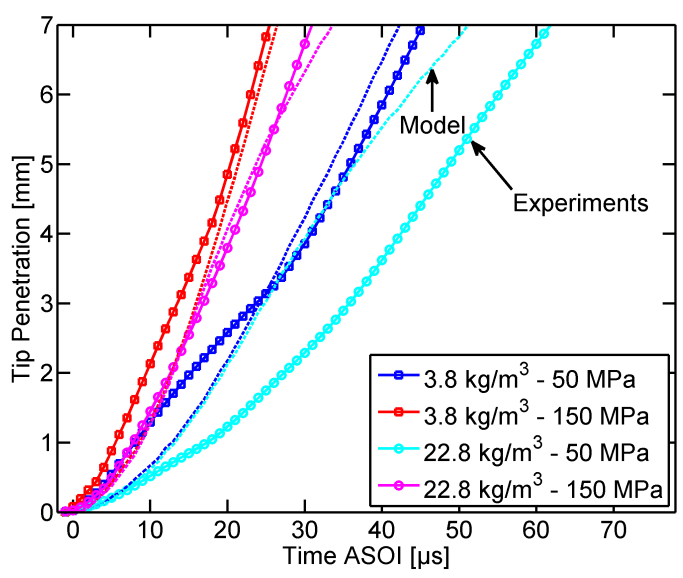

Figure 13: Penetration rates comparisons in the near-nozzle region between experiments and modeling results for two injection pressures and ambient densities.

Figure 13 compares the penetration rates measured experimentally to the results predicted by the Musculus and Kattke model with the parameters listed in Table 2, Results from two injection pressures and two ambient densities are represented. The solid lines with symbols represent the experiments, while the modeling results are plotted as dashed-lines. Note that the measured penetration rates were already reported in Fig. 3, but have been plotted in this graph for comparison purposes.

The comparisons displayed in Fig. 13 show that the penetration rates are fairly well predicted by the model for the high injection pressure conditions. Both $150 \mathrm{MPa}$ measured penetration profiles are well described by the modeling results, with discrepancy below half a millimeter. These re- 
sults for the high density and high injection pressure condition confirm the findings from Pickett et al. (2013), who reported good agreement in the near nozzle region using similar modeling setup and experimental conditions (except for the $900 \mathrm{~K}$ ambient temperature of Spray A). The lower injection pressure cases present larger discrepancies, especially the high density $(22.8$ $\left.\mathrm{kg} / \mathrm{m}^{3}\right)$, low injection pressure $(50 \mathrm{MPa})$ condition, with predicted tip penetration distance almost 2 millimeters ahead of the experimental results. The modeling results are always ahead of the experiments, and even though the divergence tends to decrease as sprays progress farther in the chamber, the differences are still substantial. It must be noted that the high resolution of the experiments, both spatially and temporally, enhances the mismatch with the predictions. The better match between predictions and experiments for the $3.8 \mathrm{~kg} / \mathrm{m}^{3}$ density, $50 \mathrm{MPa}$ injection pressure case somewhat covers the initial underestimations and later overestimations from the model. Looking closely at the $3.8 \mathrm{~kg} / \mathrm{m}^{3}$ density, $150 \mathrm{MPa}$ injection pressure curve, disagreement can be observed in the first millimeters, before both penetration rates (measured and predicted) follow a similar ramp, after approximately 4 to 5 $\mathrm{mm}$ downstream. These results provide information regarding the source of the penetration difference in the near field, revealing the effects of operating conditions on penetration.

A few explanations come to mind to support the differences between measured and simulated penetration rates for the low injection pressure cases: The "complete" mixing assumption made in the model, the spreading angle time-dependency, or inappropriate rate of injection (or injection velocity). The "complete" momentum transfer between the injected flow (liquid fuel) and the surrounding gas made by the model can be inappropriate during the start of injection due to the high density ratio between the two fluids. This means that no velocity slip is considered between the injected fuel liquid structures (or droplets) and the gas entrained in the stream. Such assumption has been validated for gas jets, but disagreement still persists among researchers regarding high-pressure liquid sprays, especially in the near-nozzle region. Faster predicted penetration rates compared to the measurements suggests that the measured sprays exchange more momentum with the ambient than is assumed by the spray model. Because the model already assumes "complete" momentum transfer, such hypothesis cannot be valid.

Another explanation to support the mismatch between measured and predicted penetration concerns the transient spreading angle of the sprays in 
the near-field. Because of the high variability of the spreading angle during the transient period of the start of injection, a time-dependent spray opening would be more appropriate. Unfortunately, the model does not allow for change in spreading angle with time in its present form. At the same time, predictions have been made using other spreading angle values as input to the model; but the results did not show substantial differences in penetration considering a reasonable range of spreading angles.

Faster tip penetration at the very beginning of the injection predicted by the model can be the result of an overestimated rate of injection during the initial ramp-up, as seen for the $22.8 \mathrm{~kg} / \mathrm{m}^{3}$ density, $50 \mathrm{MPa}$ injection pressure case of Fig 13 . One can expect similar fuel pressure build-up in the nozzle at constant rail pressure, but the importance of discharge pressure on needle lift and fuel pressure delivery is not clearly known. The experimental results show significant variation in penetration distance between the two ambient densities for the $50 \mathrm{MPa}$ injection pressure in the first $3 \mathrm{~mm}$, while the predictions are almost perfectly matched. Differences in internal flows between these two conditions are likely to explain the discrepancies. Further analysis of the internal flow and the influence of back pressure on the injector's hydraulic characteristics are necessary to generate a more appropriate rate of injection under these conditions.

Accurate prediction of the mixing field after the end of injection is necessary to obtain satisfactory combustion simulation results in spray flames. It becomes even more important when auto-ignition occurs after the end of injection, like in the low temperature combustion strategies applied to diesel engine combustion. The velocity of the flow exiting the nozzle at the end of injection and the subsequent entrainment of the surrounding gases are the main parameters driving the mixing processes after the injection has ended. Agreement between measured and predicted flow velocity at the end of injection is important as it represents the starting point for entrainment waves after injection has ended. The ramp-down period of the injection is therefore a key parameter regarding air entrainment and mixing processes at and after the end of injection. The Musculus and Kattke model has been used to compare the predicted flow velocity at the end of injection to the measured spray deceleration. The model can also provide information about air entrainment rate, mixing field and so on, once end of injection predicted flow velocity matches the experimental quantities. The rate of injection profile during this stage is paramount for the modeling results to match the experiments. 
The other parameters listed in Table 2 are also used as inputs to the model and to the rate of injection generator.

While the injection duration and model run time were not relevant parameters regarding the initial penetration rates, they are when end of injection is concerned. Because the electronic injection duration was maintained constant during the experiments, the hydraulic injection duration and thus the end of injection timing varied with operating conditions. The end of injection from the model was used as reference to time-align the measured end of injection velocities. The velocities were measured thanks to a backilluminated imaging system providing two-dimensional time-sequences in a similar fashion to the optical flow method (Horn and Schunck, 1993; Lorenz et al. 2012). The optical flow method relies on the measured motion of brightness patterns in successive images to deduce a velocity field. Examples of three image pairs are displayed in Fig. 14, showing the image correlation between pairs to obtain the displacement of the flow and thus the velocity after accounting for the inter-frame time. Note that the frame spacing was stretched later when the flow slows down to increase velocity measurement accuracy. The back-illuminated intensity fields were treated in a way similar to the windowing method used in particle image velocimetry algorithms: The images were sectored into areas of $32 \times 32$ pixels or $16 \times 16$ pixels. Crosscorrelation was then applied to identify the matching areas across an image sequence and determine the flow velocity. Droplets and structures at the end of injection were recorded with high-speed and were analyzed to extract flow velocity with respect to time. Note that only the axial component of the velocity vectors identified between 1 and $2 \mathrm{~mm}$ downstream of the orifice exit were taken into account. Because of the line-of-sight optical arrangement of the method, the optical thickness of the spray is limiting the analysis to the last instants of the injection event or later.

Comparisons of the flow velocity at the end of injection predicted by the Musculus and Kattke model and measured by the velocimetry method described above are plotted in Fig. 15. Two injection pressures (50 and 150 $\mathrm{MPa}$ ) and two ambient densities are represented in the dual panel plot, with the low density case $\left(3.8 \mathrm{~kg} / \mathrm{m}^{3}\right)$ at the top and the high density condition $\left(22.8 \mathrm{~kg} / \mathrm{m}^{3}\right)$ at the bottom. The modeling results correspond to the mean flow velocity between 1 and $2 \mathrm{~mm}$ downstream of the nozzle exit, to be comparable to the velocity measurements detailed above. The vertical errorbars on the experimental results represent the standard deviation computed over 


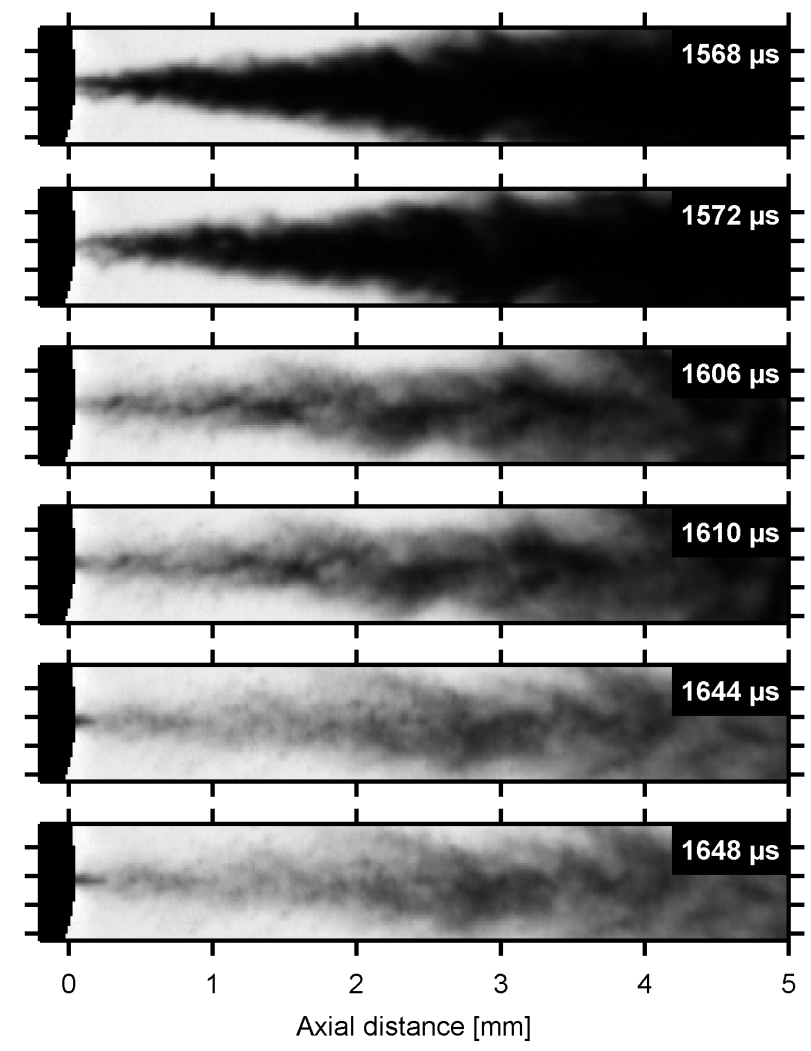

Figure 14: Normalized images of three time-correlated end of injection instants used to extract spray velocity information. Timings at the top-right corner represent the time after the start of injection. Injection pressure is $150 \mathrm{MPa}$ and ambient density is 22.8 $\mathrm{kg} / \mathrm{m}^{3}$. 

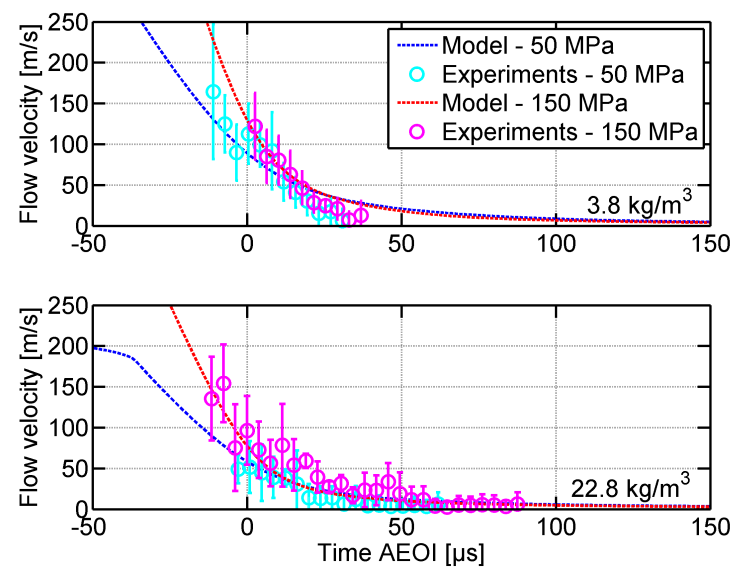

Figure 15: Comparisons between the flow velocity during the end of injection transients measured in the experiments and simulated by the spray model for two injection pressures and two ambient densities.

the measured axial velocity vectors (between 1 and $2 \mathrm{~mm}$ from the nozzle outlet) extracted from the ten repeated injections for each condition.

Even considering the relatively large variations in flow velocities extracted from the high-speed movies, the agreement between measured and predicted velocities at the end of injection is promising. These results confirm the correct ramp-down profile of the generated rate of injection, even when conditions are varied. Because the measurements rely on the velocity of the liquid flow, while the model results show the flow velocity, i.e., injected liquid and entrained gas, larger differences could be expected. This suggests that the assumption of "complete" momentum transfer made by the model is valid in the near-nozzle region at or after the end of injection. The reasonable match between measured and predicted velocities across the different conditions reduces the likelihood of combined incorrect rate of injection and incomplete momentum transfer, resulting in the results plotted in Fig. 15.

Comparisons to the (Musculus and Kattke, 2009) model proved useful as they revealed reasonable agreement during the transients of the injection. The agreement between measured and predicted penetration rates at the start of injection shown in Fig. 13 as well as the discrepancies support the need for accurate knowledge regarding boundary conditions. The differences indicated that the injection rate at the very beginning of the event might benefit from slight adjustment, but also that the model may be improved by 
implementing spreading angle time-dependency. Regarding the other end of the injection event, relatively good match was obtained by comparing measured end of injection velocities to predicted flow velocities. These measurements are highly relevant to modern thermal engines, as a large portion of the fuel mixes and burns once the injection has ended. Under regimes where the fuel ignites after the end of injection (e.g., low temperature combustion), the mixture distribution becomes even more important as it will determine when and where ignition occurs. As mentioned above, accurate knowledge of the flow velocity is paramount because it relates injected mass flow rate to spray momentum. These parameters are key to the predictions of entrainment rates and global mixing distribution, as detailed by the formulation of the model from Musculus and Kattke (2009) for example.

\section{Conclusions}

Highly spatially and temporally resolved experiments have been performed in the near-field of high-pressure sprays injected into slightly heated environments over widely varied conditions. The experiments were performed in an optically accessible high-pressure, high-temperature constant pressure flow vessel. The images have been acquired by a high-speed camera equipped with a long-distance microscope lens and the illumination was provided by a purposely-designed LED system. Two fuels (n-dodecane and ethanol) have been injected to understand the effects of boundary conditions, such as injection and ambient pressures or fuel temperature, on spray developments and injection processes in the first millimeters. Spray penetration rates and spreading angles were measured directly from the images; hydraulic delay and spray velocity during the transients were computed based on the timeresolved data available.

The measurements showed an increase in penetration velocity at the very beginning on the injection: this behavior is principally related to the mass flow rate ramp-up during the opening transient and suggests a build-up period of the fuel pressure within the nozzle. The results demonstrated the impact of outlet flow on spray development as lower penetration velocities and wider spreading angles were measured during the quasi-steady period of injection than during the transient start and end of injection parts. The transient period observed in the spreading angle results was linked to the injector needle position. During the opening and closing transients, the flow passage around the needle is very small: This throttling of the fuel flow in 
this region is believed to affect the flow exiting the orifice as well as spray formation. The two fuels used in the experiments (n-dodecane and ethanol) only showed slight variations in tip penetration, but the effect on spreading angle was substantial, with wider sprays when ethanol was injected. Increasing fuel temperature proved to slow down the tip penetration of the sprays, but the spreading angle measurements did not show noticeable differences. Fuel temperature affects injector performance with a reduction of the delay between electronic signal and actual hydraulic injection. Comparisons of the measured penetration rates to the predictions from a control-volume spray model highlighted the need for accurate boundary conditions. Predictions using the spray model regarding flow velocity at the end of injection agreed well with the measurements of the injected flow velocity during injector closing and later. These results consolidate the complete mixing assumptions made by the spray model in the near-nozzle region, at least at and after the end of injection.

\section{Acknowledgments}

The authors wish to thank Chris Carlen from Sandia National Laboratories for designing and manufacturing specific ultra-fast LEDs, as well as Jose Enrique del Rey and Juan Pablo Viera from CMT-Motores Termicos for their support during the experiments. Support for the research carried out by Julien Manin at CMT-Motores Termicos was provided by the U.S. Department of Energy, Office of Vehicle Technologies. Sandia is a multiprogram laboratory operated by Sandia Corporation, a Lockheed Martin Company for the United States Department of Energy's National Nuclear Security Administration under contract DE-AC04-94AL85000.

\section{References}

Apte, S.V., Gorokhovski, M., Moin, P., 2003. LES of atomizing spray with stochastic modeling of secondary breakup. International Journal of Multiphase Flow 29, 1503-1522.

Bae, C., Kang, J., 2006. The structure of a break-up zone in the transient diesel spray of a valve-covered orifice nozzle. International Journal of Engine Research 7, 319-334. 
Bardi, M., Payri, R., Malbec, L.M., Bruneaux, G., Pickett, L.M., Manin, J., Bazyn, T., Genzale, C.L., 2012. Engine Combustion Network (ECN): Comparison of spray development, vaporization and combustion in different combustion vessels. Atomization And Sprays 22, 807-842.

Brown, J.D., 1988. Understanding research in second language learning: A teacher's guide to statistics and research design. Cambridge University Press.

Caudwell, D.R., Trusler, J.P.M., Vesovic, V., Wakeham, W.A., 2004. The viscosity and density of n-dodecane and n-octadecane at pressures up to $200 \mathrm{MPa}$ and temperatures up to $473 \mathrm{~K}$. International Journal of Thermophysics 25, 1339-1352.

Crua, C., de Sercey, G., Heikal, M.R., M., G., 2012. Dropsizing of near-nozzle Diesel and RME sprays by microscopic imaging. ICLASS 2012, Heidelberg, Germany .

Desantes, J.M., Payri, R., Garcia, A., Manin, J., 2009. Experimental study of biodiesel blends effects on Diesel injection processes. Energy \& Fuels 23, 3227-3235.

Desantes, J.M., Payri, R., Salvador, F.J., Gil, A., 2005. Development and validation of a theoretical model for diesel spray penetration. Fuel 85, 910-917.

Fansler, T.D., Parrish, S.E., 2015. Spray measurement technology: a review. Measurement Science and Technology 26, 012002.

Ghandhi, J.B., Heim, D.M., 2009. An optimized optical system for backlit imaging. Review of Scientific Instruments 80, 056105.

Heimgartner, C., 2000. Investigation of the primary spray breakup close to the nozzle of a common-rail high-pressure Diesel injection system. SAE Paper 2000-01-1799 .

Horn, B.K.P., Schunck, B.G., 1993. Determining optical flow: a retrospective. Artificial Intelligence 59, 81-87.

Kastengren, A., Tilocco, Z., Powell, P., 2011. Initial evaluation of engine combustion network injectors with X-Ray diagnostics. ILASS-Americas 2011, Ventura, CA . 
Kastengren, A.L., Tilocco, F.Z., Powell, C.F., Manin, J., Pickett, L.M., Payri, R., Bazin, T., 2012. Engine Combustion Network (ECN): Measurements of nozzle diameter and hydraulic behavior. Atomization And Sprays 22, 1011-1052.

Lai, M.C., Wang, T.C., Xie, X.B., Han, J.S., Henein, N., Schwarz, E., Bryzik, W., 1998. Microscopic characterization of diesel sprays at VCO nozzle exit. SAE Transactions 107, 1284-1292.

Lorenz, S., Goldlucke, J., Straub, D., Bruggemann, D., 2012. Spray velocity field analysis with optical flow method-an alternative to particle image velocimetry. ICLASS 2012 conference, Heidelberg, Germany 1180.

Manin, J., Bardi, M., Pickett, L.M., Dahms, R.N., Oefelein, J.C., 2014. Microscopic investigation of the atomization and mixing processes of diesel sprays injected into high pressure and temperature environments. Fuel 134, $531-543$.

Manin, J., Kastengren, A., Payri, R., 2012. Understanding the acoustic oscillations observed in the injection rate of a common-rail direct injection diesel injector. Journal of Engineering for Gas Turbines and Power 134, 122801.

Meijer, M., Somers, B., Johnson, J., Naber, J., Lee, S.Y., Malbec, L.M., Bruneaux, G., Pickett, L.M., Bardi, M., Payri, R., Bazyn, T., 2012. Engine Combustion Network (ECN): characterization and comparison of boundary conditions for different combustion vessels. Atomization and Sprays 22, 777-806.

Musculus, M.P.B., Kattke, K., 2009. Entrainment waves in diesel jets. SAE International Journal of Engines 2, 1170-1193.

Naber, J.D., Siebers, D.L., 1996. Effects of gas density and vaporization on penetration and dispersion of diesel sprays. SAE Paper 960034.

Payri, R., Garcia-Oliver, J.M., Bardi, M., Manin, J., 2012. Fuel temperature influence on Diesel sprays in inert and reacting conditions. Applied Thermal Engineering 35, 185-195. 
Payri, R., Gimeno, J., Bardi, M., Plazas, A.H., 2013. Study liquid length penetration results obtained with a direct acting piezo electric injector. Applied Energy 106, 152-162.

Payri, R., Salvador, F.J., Gimeno, J., De la Morena, J., 2008. Macroscopic behavior of diesel sprays in the near-nozzle field. SAE Paper 2008-01-0929

Pickett, L.M., Manin, J., Genzale, C.L., Siebers, D.L., Musculus, M.P.M., Idicheria, C.A., 2011. Relationship between diesel fuel spray vapor penetration/dispersion and local fuel mixture fraction. SAE Paper 2011-01-0686 - SAE Int. J. Engines 4, 764-799.

Pickett, L.M., Manin, J., Kastengren, A., Powell, C., 2014. Comparison of near-field structure and growth of a diesel spray using light-based optical microscopy and x-ray radiography. SAE Paper 2014-01-1412 - SAE Int. J. Engines 7.

Pickett, L.M., Manin, J., Payri, R., Bardi, M., Gimeno, J., 2013. Transient rate of injection effects on spray development. SAE Paper 2013-24-0001 .

Shoba, T., Crua, C., Heikal, M., Gold, M., 2011. Optical characterisation of diesel, RME and kerosene sprays by microscopic imaging. ILASS-Europe 2011, Estoril, Portugal .

Vuorinen, V., Antila, E., Kaario, O., Larmi, M., El-Hannouny, E., Gupta, S., 2006. Near nozzle diesel spray modelling and x-ray measurements. SAE Paper 2006-01-1390 . 